\title{
Updating existing QSAR models: selection and weighting of new data
}

\author{
Tomas Öberg ${ }^{*}$, T Liu \\ From 5th German Conference on Cheminformatics: 23. ClC-Workshop \\ Goslar, Germany. 8-10 November 2009
}

Computational chemistry and quantitative structureactivity relationships (QSAR) are foreseen to be extensively used in the implementation of the new REACH regulation for chemicals in Europe. However, for some compound groups the data are too few in number to permit both calibration and testing of a new model. Usage and previously developed or updated models are then viable alternatives.

Perfluorocarboxylic acids (PFCAs) and fluoroteleomer alcohols (FTOHs) are two groups of environmentally relevant compounds, with unique physical and chemical properties. The subcooled liquid vapour pressure (pL) is one such property, where experimental determinations are limited and far from consistent [1]. Updating is, however, challenging when the new compounds are far outside of the original calibration domain space. But by carefully selecting and weighting only three new compounds, we have been able to update a previously developed general QSAR model [2], to cover the new domain while maintaining predictive performance for the earlier calibration and test data. The optimal weighting scheme was determined from the sample leverages and residuals in the calibration phase [3].

The performance of this re-calibrated model greatly surpassed previous modelling attempts [4], when applied to an external test set of two PFCAs and four FTOHs with $\mathrm{pL}$ in the range $0.2-200 \mathrm{~Pa}$; with Q2Ext $=0.994$ and RMSEP $=0.190$ units of $\log \mathrm{Pa}$. The domain coverage also increased from $1 \%$ to $51 \%$, for 426 perfluoroalkylated compounds selected from the REACH registration list, the PhysProp database, and the OECD 2006 survey [5]. Selection and weighting of new calibration data can thus facilitate the extension and use of existing QSAR models.

University of Kalmar, Sweden
This investigation was supported by the EU FP7 project CADASTER (grant agreement no. 212668).

Published: 4 May 2010

\section{References}

1. Goss K-U, Bronner G, Harner T, Hertel M, Schmidt TC: Environ Sci Technol 2006, 40:3572.

2. Öberg T, Liu T: QSAR Comb Sci 2008, 27:273.

3. Stork CL, Kowalski BR: Chemometr Intell Lab Syst 1999, 48:151.

4. Arp HP, Niederer C, Goss K-U: Environ Sci Technol 2006, 40:7298.

5. Lists of PFOS, PFAS, PFOA, PFCA, related compounds and chemicals that may degrade to PFCA. ENV/JM/MONO(2006)16, OECD. 2007.

doi:10.1186/1758-2946-2-S1-P19

Cite this article as: Öberg and Liu: Updating existing QSAR models: selection and weighting of new data. Journal of Cheminformatics 2010 2(Suppl 1):P19.

\footnotetext{
Publish with ChemistryCentral and every scientist can read your work free of charge

"Open access provides opportunities to our colleagues in other parts of the globe, by allowing anyone to view the content free of charge." W. Jeffery Hurst, The Hershey Company.

- available free of charge to the entire scientific community

- peer reviewed and published immediately upon acceptance

- cited in PubMed and archived on PubMed Central

- yours - you keep the copyright

Submit your manuscript here:

http://www.chemistrycentral.com/manuscript/

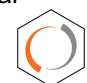
Chemistry Central
} 